\title{
The need for financial knowledge acquisition tools and technology by small business entrepreneurs
}

\author{
Panita Rachapaettayakom ${ }^{1 *}$ (D) Mongkolchai Wiriyapinit ${ }^{2}$, Nagul Cooharojananone ${ }^{3}$, \\ Suparatana Tanthanongsakkun ${ }^{4}$ and Nuttirudee Charoenruk ${ }^{5}$
}

\author{
* Correspondence: \\ Rachapaettayakom@gmail.com \\ ${ }^{1}$ Technoprenurship and Innovation \\ Management Program, Graduate \\ School, Chulalongkorn University, \\ Bangkok, Thailand \\ Full list of author information is \\ available at the end of the article
}

\begin{abstract}
Knowledge management tools and technology are the main factors bringing competitive advantage to organisations. This study extends the depth of study on small business entrepreneurs by examining the effect of knowledge acquisition, in particular financial knowledge that leads to the need for knowledge acquisition tools and technology. There is evidence to support that a lower level of existing financial knowledge in small business entrepreneurs encourages them to acquire more financial knowledge since they tend to be responsible for all tasks related to business survival. This finding is not consistent with several other previous studies. In addition, relevant knowledge on how to raise adequate capital to establish their business and the accurate calculation of cost are the two most important aspects of financial knowledge for encouraging small business entrepreneurs to seek effective knowledge acquisition tools and technology. The evidence provides insight for the government authorities supporting small businesses to provide financial knowledge to small business entrepreneurs during the pre-start-up phase and thereafter by providing the relevant knowledge on financing and cost calculation to strengthen and sustain these businesses. This will ultimately lead to an improvement in small business failure and increase the country's economic growth.

Keywords: Knowledge acquisition, Financial knowledge, Small business entrepreneurs, Tools and technology, Restaurant business
\end{abstract}

\section{Springer Open}

\section{Introduction}

The small businesses play an important role in contributing to the essential economic growth of many countries in the world, creating income and job creation. Although small businesses are the main drivers of economic growth, numerous small business entrepreneurs face failure (Hyder \& Lussier, 2016). Small business entrepreneurs play multiple roles in the management of their businesses (Fuller-Love, 2006) and responses to business performance (Durst \& Edvardsson, 2012). Although these entrepreneurs need information and knowledge to support their decision-making and problem

(c) The Author(s). 2020 Open Access This article is licensed under a Creative Commons Attribution 4.0 International License, which permits use, sharing, adaptation, distribution and reproduction in any medium or format, as long as you give appropriate credit to the original author(s) and the source, provide a link to the Creative Commons licence, and indicate if changes were made. The images or other third party material in this article are included in the article's Creative Commons licence, unless indicated otherwise in a credit line to the material. If material is not included in the article's Creative Commons licence and your intended use is not permitted by statutory regulation or exceeds the permitted use, you will need to obtain permission directly from the copyright holder. To view a copy of this licence, visit http://creativecommons.org/licenses/by/4.0/. 
solving, they tend to have limited financial knowledge (Hodges \& Kent, 2006), ultimately leading to business failure.

According to the Office of Small and Medium Enterprises Promotion (OSMEP), small businesses in Thailand account for an estimated 30\% of Gross Domestic Product (GDP) (OSMEP, 2017). In recent years, the country's economic growth has expanded due to the considerable increase in tourism (OSMEP, 2017). The small restaurant business has benefitted from the continuous expansion of the tourism industry, contributed an estimated 15\% of GDP of small businesses (OSMEP, 2017). However, the failure rate of such businesses is very high. A reasonable explanation for more than $60 \%$ of restaurants failing (OSMEP, 2017) may be because small-restaurant entrepreneurs ("restaurant entrepreneurs") can easily open a restaurant, even though they lack knowledge and experience, often resulting in closure after 3 years (Rachapaettayakom, Wiriyapinit, Cooharojananone, \& Tanthanongsakkun, 2018). Therefore, this study focuses on the need for financial knowledge acquisition tools and technology in this business sector.

There are many prior studies on knowledge acquisition in large organisations. Papa, Dezi, Gregori, Mueller, \& Miglietta, 2018 indicated that knowledge acquisition affects business performance in large organisations, but such organisations provide in-house software to assist knowledge acquisition (Laudon \& Laudon, 2002), while small businesses lack the tools and technology necessary for accessing information resources. These studies do not provide a comprehensive explanation for knowledge acquisition, financial knowledge, prior financial knowledge, and the need for knowledge acquisition tools and technology in a particular sector such as the restaurant business, resulting in research gaps.

Continuing research on small business entrepreneurs is important due to their valuable contribution to the economic growth of the country. Knowledge acquisition tools and technology ("KA tools") will enhance the ability and accessibility for them to gain more information, knowledge, and understanding on financial knowledge, promoting business performance, improving sustainability, and reducing the failure rate of small businesses.

The current high restaurant business failure rate and research gaps lead to the research questions: (1) What is the relationship between the level of prior or existing financial knowledge and level of knowledge acquisition? (2) What is the relationship between the level of existing financial knowledge and level of need for financial knowledge acquisition tools and technology? (3) What is the relationship among the level of each financial knowledge acquisition aspect and level of need for financial KA tools in order to comprehensively satisfy the requirements of small business entrepreneurs, particularly in the restaurant business, to fill the gap in current studies?

This study makes an academic contribution to the literature in a number of ways. Firstly, this research draws on existing theory and extends a model of knowledge acquisition whereby the base level of prior knowledge (Roper \& Love, 2017) indicates the level of knowledge acquisition that effects on the decision-making skill (Kheradmand \& Jafari, 2015) of entrepreneurs, enhancing business performance (Song, Min, Lee, \& Seo, 2017). Secondly, this study contributes by building on the current literature and extending the importance of financial knowledge for small business success such as financing, record keeping and accounting, cash management, business planning (Hyder \& Lussier, 2016), cost calculation (Oyadomari, Silva, Mendonça Neto, \& Diehl, 2017), and 
a feasibility study (Okon \& Morgan, 2018) that lead to need for KA tools for small business entrepreneurs in particular of a restaurant business.

In contrast to previous studies, the findings from this study indicate that a lower level of existing financial knowledge leads to a higher level of financial knowledge acquisition due to the characteristics of restaurant entrepreneurs as new entrants, taking a central position with responsibility for business performance (Bridge, O'Neill, \& Cromie, 2003). Therefore, they have to seek information, knowledge, and expertise to enable their business to survive which is consistent with the study by Bridge et al. (2003).

In addition, the findings from this study indicate that financial knowledge acquisition when applying for a loan from the bank is essential for small business entrepreneurs. This is consistent with the studies by Hyder \& Lussier (2016) in that adequate capital is one of the main contributory factors for business success. Therefore, the level of need for KA tools is greater when applying for a loan. Information asymmetry is an obstacle for small business entrepreneurs (Moy \& Luk, 2003; Orser, Hogarth-Scott, \& Riding, 2000). However, KA tools provide restaurant business entrepreneurs with access to appropriate sources of financing for the sustainability and survival of their businesses. The results of this study will be beneficial to government agencies, academics, practitioners, and financial institutions in developing strategies to support KA tools for small business entrepreneurs to improve their chances of success.

Section 2 of this paper provides a literature review, hypotheses, and research framework. Section 3 constructs the methodology, data collection instruments, validity and reliability, variables and measure, samples, and data collection. It also describes the empirical statistics used to test the hypotheses. Section 4 demonstrates the results and analysis. Section 5 presents the discussion. Finally, Section 0 explains the conclusions along with the contribution of this study, as well as providing suggested avenues for further research.

\section{Literature review, hypotheses, and research framework Small business entrepreneurs}

According to Soundararajan, Jamali, \& Spence (2018), small businesses are defined in several ways, such as the number of employees, investment capital, total assets, and sales volume. Small businesses contribute to a nation's economic growth, creating income and jobs (Durst \& Bruns, 2018), especially in developing countries (Ratten, 2014). Despite their significant economic contribution, numerous small business entrepreneurs face business failure (Hyder \& Lussier, 2016). This may be because small business entrepreneurs tend to focus on day-to-day survival (Soundararajan, Spence, \& Rees, 2016) and have to play multiple business management roles, including operation, sales, and finance (Fuller-Love, 2006) as well as being responsible for business performance (Durst \& Edvardsson, 2012). They need information, knowledge, and expertise in order to support decision-making and problem-solving.

However, small business entrepreneurs tend to have limited knowledge, particularly regarding financial knowledge analysis (Hodges \& Kent, 2006). Poor financial knowledge is likely to lead to the failure of many small businesses (Tushabomwe-Kazooba, 
2006). Joo \& Grable (2000) support the view that entrepreneurs make inappropriate and ineffective financial decisions because they lack the relevant knowledge and have insufficient time to learn about financial management. This problem leads to ineffective decision-making and may ultimately result in business failure (Kotzè \& Smit, 2008).

Small business entrepreneurs faced with the challenge of insufficient financial knowledge are likely to find it difficult to raise adequate capital for sustaining the business, effective record keeping and accounting, specific business planning, efficient cash management (Hyder \& Lussier, 2016), cost measurement (Oyadomari et al., 2017), and a proper feasibility study (Okon \& Morgan, 2018).

\section{Small restaurant entrepreneurs in Thailand}

In Thailand, small businesses are defined as companies with fewer than 50 workers (OSMEP, 2017). In 2016, the economic growth of Thailand expanded more rapidly than the previous year due to the considerable expansion of the tourism industry (OSMEP, 2017). Small restaurant businesses obtained substantial benefits from such expansion. Small businesses accounted for an estimated 30\% of GDP and generated more than 70\% of all employment (OSMEP, 2017). The small restaurant business contributed an estimated 15\% of GDP of small businesses (OSMEP, 2017). However, the failure rate of a small restaurant business is very high at more than 60\% (OSMEP, 2017).

Although restaurant entrepreneurs tend to have no prior knowledge or relevant experience in restaurant business management, they can open a restaurant since no rules and regulations apply to small restaurants in Thailand. In addition, restaurant entrepreneurs carry out the day-to-day business operations due to the attention to detail required. This often means there are time constraints for the acquisition of knowledge. As a result, restaurant entrepreneurs tend to lack the necessary relevant financial knowledge. This may explain the high restaurant business failure rate, with such enterprises often closing down within 3 years (Rachapaettayakom et al., 2018). KA tools may support restaurant entrepreneurs in gaining greater financial knowledge relevant to restaurant business management to sustain their businesses and decrease the failure rate.

\section{Knowledge acquisition}

Liao, Wu, Hu, and Tsui (2010) defined knowledge acquisition as a process of acquiring and using knowledge, based on existing knowledge. Liao and Barnes (2015) believe that acquiring knowledge is the activity of accepting knowledge from the external environment. While Cho \& Korte (2014) explained that knowledge acquisition involves the process of acquiring knowledge from either inside or outside the organisation. Liu \& Deng (2015) support the view that knowledge acquisition is perceived as an important success factor for entrepreneurs in achieving and sustaining competitive advantage. Entrepreneurs may acquire external knowledge by observing, imitating, practising, and interacting with others such as experts, customers, suppliers, and competitors for future business opportunities and gaining competitive advantage (Cho \& Korte 2014). Kheradmand and Jafari (2015) support the view that knowledge acquisition also affects the decision-making skills crucial for entrepreneurs since it strengthens entrepreneurial competitiveness (Song et al., 2017). Therefore, knowledge acquisition can be expected to have a significant influence on business performance (Ha, Lo, \& Wang, 2016). 
According to Cohen and Levinthal (1990), individuals who are not knowledgeable about a certain topic will not actively search to expand their knowledge. While Roper \& Love (2017) suggest that the level of knowledge acquisition is determined by the base level of prior or existing knowledge. Based on these previous studies, the researchers therefore extend the research in the context of small restaurant entrepreneurs in respect of financial knowledge. As a result, the first hypothesis is proposed.

H1 Higher level of existing financial knowledge in restaurant entrepreneurs is positively related to the level of financial knowledge acquisition

\section{Knowledge acquisition tools and technology}

Technology is commonly present in almost every domain of contemporary society. The development of technology and access to the Internet has resulted in the implementation of many knowledge delivery systems (Stal \& Paliwoda-Pekosz, 2017). According to Hwang and Wu (2014), technology utilisation occurs in numerous domains, such as industrial applications and the field of education. However, technology adoption in systematic knowledge acquisition remains scarce (Stal \& Paliwoda-Pekosz, 2017).

According to Cho \& Korte (2014), knowledge management tools are the most important enablers of active knowledge management processes and may include social media and social networks such as websites, Facebook, Line, and blogs (Ghani 2009). Despite the variety of KA tools, none are stand-alone (Tyndale, 2002). Many KA tools have been developed according to strategies for solving the knowledge acquisition problem (Ghani 2009).

There are limited previous studies in KA tools in small business. Large organisations provide in-house software for knowledge management to improve their efficiency (Rafea, Hassenb, \& Hazmanc, 2003), while small businesses have limited tools for accessing information resources from outsiders. In comparison to larger organisations, small business entrepreneurs might require different tools and technology or use such tools and technology differently to survive (Unger, Rauch, Frese, \& Rosenbusch, 2011). However, the entrepreneurs cannot develop the tools and technology on their own due to financial limitations. The lack of financial knowledge resources and effective knowledge acquisition tools means that small business entrepreneurs are likely to face business failure (Bridge et al., 2003).

According to Aghaei, Nematbakhsh, and Farsani (2012), social media and social networks such as websites Facebook, Line, and blogs are used by these entrepreneurs to enhance their knowledge acquisition opportunities. Since entrepreneurs may need to acquire more knowledge, they can become highly reliant on knowledge acquisition tools. The different levels of need for tools to acquire specific financial knowledge on business management, and the various uses for particular knowledge acquisition tools, are influenced by the factors surrounding the small business environment (Wee \& Chua, 2013).

In order to extend the previous studies on knowledge acquisition and knowledge infrastructure (Cho \& Korte, 2014), the researchers expect the level of knowledge acquisition in relation to financial knowledge to relate to the level of need for knowledge acquisition tools by small business entrepreneurs. Therefore, based on literature review, the following hypothesis is proposed. 
$\mathrm{H} 2$ Higher levels of existing financial knowledge in restaurant entrepreneurs is positively related to the level of need for financial knowledge acquisition tools and technology.

\section{Financial knowledge of small business entrepreneurs}

Huston (2010) described financial knowledge as measuring how well an individual can understand and be confident to use their financial knowledge make a financial decision. According to Ali et al. (2018), financial knowledge is the ability to manage financial matters, while Jindrichovska (2013) proposes that there are entrepreneurs who start a business but have not involved themselves in managing the financial aspects.

Van Auken (2005) supported that a limited understanding of financial knowledge is likely to be an obstacle to successful strategies. Small business entrepreneurs are responsible for business performance, growth, and sustainability; therefore, effective financial knowledge management can significantly support the achievement of their duties and responsibilities (Schierjott, Brennecke, \& Rank, 2018). However, it must be accepted that most small business entrepreneurs have time constraints and limited resources, often resulting in inadequate financial knowledge (Wong \& Aspinwall, 2004) and insufficient skills for effective business management, subsequently leading to a business failure (Ali, Omar, Nasir, \& Osman, 2018).

According to previous studies, to avoid business failure, entrepreneurs should have knowledge for financing in order to raise adequate capital, record keeping and accounting management, cash management, business planning (Hyder \& Lussier, 2016), effective cost calculation (Oyadomari et al., 2017), and a specific feasibility study (Okon \& Morgan, 2018) as follows.

Financing Financial knowledge relevant to financing is how to raise adequate capital that is one of the main contributory factors to small business success (Hyder \& Lussier, 2016). Entrepreneurs with financial knowledge tend to keep comprehensive business financial records, thereby gaining a competitive advantage over rivals who keep no such records, through their ability to access external funding (Usama \& Yusoff, 2018). The method of financing is a critical success factor for small businesses (Taiwo, 2016). Small business entrepreneurs may not be able to borrow from banks at all or tend to be offered unfavourable lending conditions (Luo, Wang, \& Yang, 2016). Financing obstacles are considered to be major growth-limiting factors for small-sized firms (Kumar \& Rao, 2016). In order to obtain adequate loan from a financial institution, the accessibility to sufficient financial information asymmetries are obstacles for small business entrepreneurs (Moy \& Luk, 2003).

In Thailand, it is often difficult for new entrepreneurs of less than 3 years standing to obtain finance from commercial banks since it is the policy of such banks to prevent non-performing loans, while government-supported banks provide loans for the new entrants. Due to financial information asymmetries and lack of KA tools, these new entrants cannot source information from government-supported banks in order to obtain loans from these banks to start their businesses. 
Based on financial information asymmetries, KA tools can help entrepreneurs to gain knowledge for financing decision-making and raise appropriate funds. The researchers therefore propose the following hypothesis:

H3a: There is a positive relationship between the level of knowledge acquisition for financing and the level of need for financial knowledge acquisition tools and technology.

Record keeping and accounting Several studies suggest that record keeping and accounting is a mechanism for performance enhancement (Scapens \& Bromwich, 2001). Ng Harrison and Akroyd (2013) support that knowledge relevant to record keeping and accounting can improve small business failure rates since a lack of sufficient financial information about their businesses lead to financial problems. It is recognised that accurate record keeping is important for the success of small businesses (Mutua, 2015).

Record keeping and accounting are useful sources of relevant financial information and contribute to effective decision-making (Kim \& Im, 2017), While Shallow (2017) supports the view that accurate record keeping and accounting enables the efficient financial management of small businesses. However, many small business entrepreneurs have limited knowledge of record keeping and accounting, despite their importance (Hodges \& Kent, 2006). They usually manage record keeping and accounting ideas in their mind rather than recording data (Berry, Sweeting, Goto, \& Taylor, 2002).

Orobia, Byabashaija, Munene, Sejjaaka and Musinguzi (2013) support that small businesses provide low sales volume, and there are no strict regulations or incentives for producing financial reports; therefore, small business entrepreneurs tend to use informal and simple record keeping and accounting techniques (Halabi, Barrett, \& Dyt, 2010). They are reluctant to invest in sophisticated and expensive record keeping and accounting systems, especially if they are unsure of the benefits (McMahon, 2001). These may ultimately lead to business failure. Since financial knowledge relevant to record keeping and accounting is necessary for small business entrepreneurs in order to get business success, the related tools and technology for acquiring such knowledge can help their survival. The researchers, therefore, propose the following hypothesis:

H3b: There is a positive relationship between the level of knowledge acquisition for record keeping and accounting, and the level of need for financial knowledge acquisition tools and technology.

Cash management In general, cash management refers to the manner in which a business manages its cash flow cycle, such as defining the timing of cash inflows and cash outflows (Nwarogu \& Iormbagah, 2017). Cash management is important for all businesses since it strengthens their financial management and survival (Ahmad, 2016). Although cash management is an important practice, many small business entrepreneurs manage their businesses without the appropriate cash management skills (Ondiek et al., 2013).

Many small business entrepreneurs fail to perform cash management practices because they believe them to be very time-consuming (Mungal \& Garbharran, 2014). Uwonda \& Okello (2013) found that the failure to manage cash is often linked to the failure of small businesses. Since financial knowledge in cash management is necessary 
for small business entrepreneurs, tools and technology for its acquisition can help such businesses survive. The researchers, therefore, propose the following hypothesis:

H3c: There is a positive relationship between the level of knowledge acquisition in cash management and the level of need for financial knowledge acquisition tools and technology.

Cost calculation Cost calculation is regarded by Oyadomari, Silva, Mendonca Neto \& Diehl (2017) as not being widely practised in small businesses. As well as restaurant entrepreneurs, they do not allocate the operating cost into menu items when prices are established (Kostakis, Albayrak, Boskou, \& Palisidis, 2011). Consequently, they do not always know the true profitability of their various menu items (Raab, Mayer, \& Shoemaker, 2010) and this can ultimately lead to business failure.

Given the existing literature on financial knowledge acquisition for small business entrepreneurs, the researchers propose that those with a higher level of financial knowledge acquisition in cost calculation will likely require more KA tools. The researchers, therefore, propose the following hypothesis:

H3d: There is a positive relationship between the level of knowledge acquisition in cost calculation and the level of need for financial knowledge acquisition tools and technology.

Business planning A business plan is a specific roadmap for entrepreneurs (Lange, Mollov, Pearlmutter, Singh, \& Bygrave, 2007) that plays an important role in entrepreneurial success (Long, Geng, \& Shakeel, 2016). Written business plans provide an overview for entrepreneurs, helping them to focus on their objectives, operational tasks, and strategies (Brinckmann, Grichnik, \& Kapsa, 2010), as well as being an advantageous tool for planning their overall activities, enhancing performance (Hopp \& Greene, 2018), and supporting the acquisition of funds from banking institutions (Lange et al., 2007). Numerous studies show that planning leads entrepreneurs towards superior performance with overall growth and success (Frederiksen \& Brem, 2016; Honig \& Samuelsson, 2020; McKenzie, 2017). Small business entrepreneurs that do not develop specific business plans have a greater chance of failure (Hyder \& Lussier, 2016).

Given the advantages of writing a business plan, the tools and technology for acquiring related knowledge can support entrepreneurs in business survival. The researchers, therefore, propose the following hypothesis:

H3e: There is a positive relationship between the level of knowledge acquisition in formulating a business plan and the level of need for financial knowledge acquisition tools and technology.

Feasibility study A feasibility study is a pre-start-up and strategic planning tools for application in the pre-business start-up phase (Currie \& Wesley, 2010). It involves a process of collecting and analysing data prior to the new business start-up (Sangree \& David, 2012). The feasibility study is especially a financial tool for deciding whether or not to go ahead before a considerable investment is made (Halil, Nasir, Hassan, \& Shukur, 2016). 
According to Okon \& Morgan (2018), the feasibility study affects small business performance and business survival. However, many small business entrepreneurs have limited knowledge of feasibility study due to their lack of a business education (Hodges \& Kent, 2006) and limited experience in business management, subsequently leading to business failure ((Beverland \& Lockshin, 2001; Marriott \& Marriott, 2000).

Given the advantages of feasibility study, the tools and technology for acquiring related knowledge can support entrepreneurs in decision-making whether or not to go ahead the business investment. The researchers, therefore, propose the following hypothesis:

H3f: There is a positive relationship between the level of knowledge acquisition in a feasibility study and the level of need for financial knowledge acquisition tools and technology.

Based on this study and the proposed hypotheses, the researchers summarise the expected relationship among level of existing financial knowledge in relevant restaurant business management, level of financial knowledge acquisition, and level of need for KA tools as shown in Fig. 1.

\section{Methodology}

According to Zait \& Zait (2009), the methodological option supports the establishment of an appropriated research strategy for accessing research problems and achieving the desired objectives. The choice of qualitative, quantitative, or mixed methods affects the study results (Zait, 2015). This study involves two design phases: the qualitative approach for gaining insight into the participants, and the quantitative approach for obtaining generalisable data, and investigating relationships.

\section{Qualitative approach}

\section{Data collection instruments}

Since there is no existing data relevant to small restaurant business entrepreneurs in Thailand, the researchers collected primary data through in-depth interviews. As the

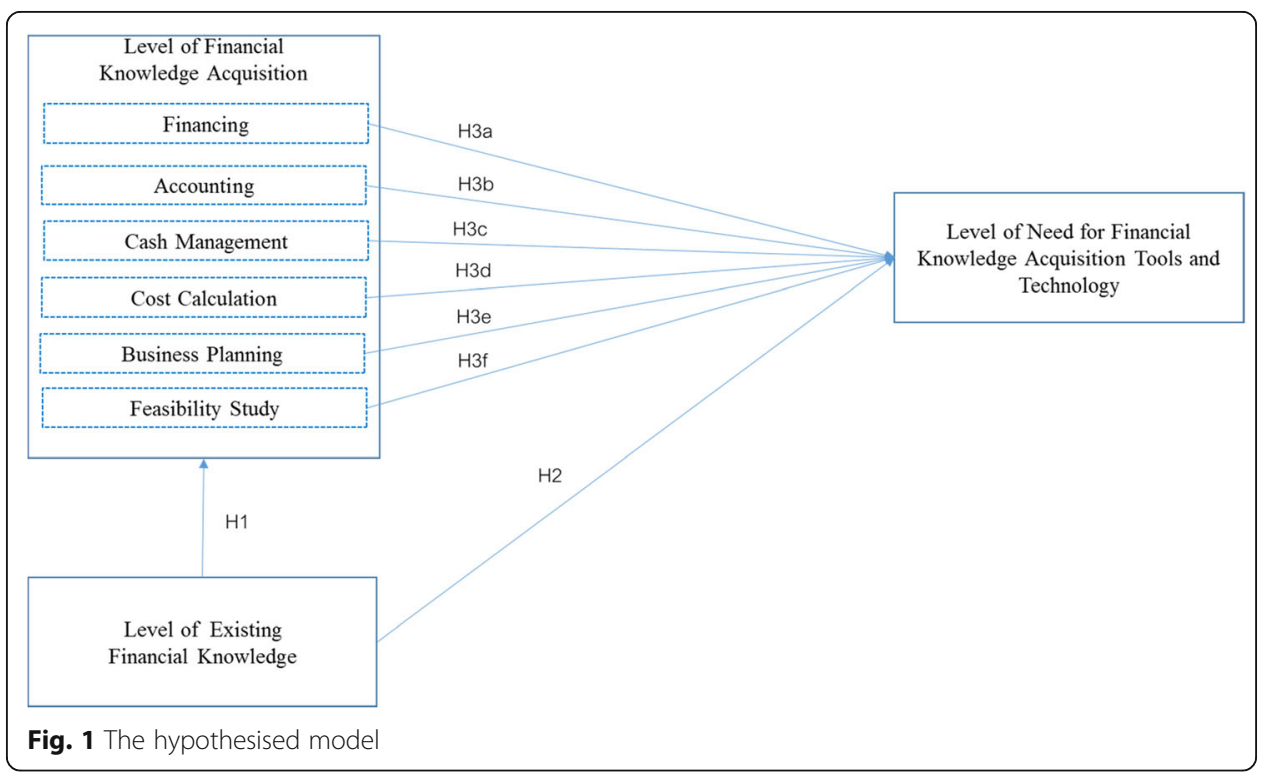


methodological option, a semi-structured questionnaire, based on the literature review was developed as a data collection instrument for collecting primary data (see Appendix 1). The objective of using a semi-structured questionnaire for data collection during in-depth interviews is to obtain the insight of small restaurant business entrepreneurs as to their existing financial knowledge, financial knowledge acquisition, and the need for financial knowledge acquisition tools in order to develop a survey questionnaire.

Eighteen restaurant entrepreneurs participated in the in-depth interviews. The indepth interviews were taped and later transcribed. The researchers used content and thematic analysis to allow data to be divided into information-rich quotations. The quotations were ultimately placed into thematic categories in line with the prior knowledge, knowledge acquisition, financial knowledge of small business entrepreneurs, and their use of KA tools. After completion of in-depth interviews and content analysis, the researchers developed items for a survey questionnaire to test the research hypotheses.

\section{Quantitative approach}

\section{Data collection instrument}

The researchers use a survey questionnaire as data collection instrument. The questionnaire was developed through an extensive literature review and information-rich quotations applying content and thematic analysis to the 18 in-depth interviews. According to the methodological option (Zait, 2015), the objective of survey questionnaire using is to obtain data that can be generalisable, and investigate the relationship among the level of small restaurant entrepreneurs' existing financial knowledge relevant to restaurant business management ("level of existing financial knowledge"), level of financial knowledge acquisition relevant to restaurant business management ("level of financial knowledge acquisition"), and the level of need for financial knowledge acquisition tools and technology relevant to restaurant business management ("level of need for financial knowledge acquisition tools").

The questionnaire consisted of four sections. Section 1 contained the demographic and background information of respondents. Section 2 comprised six items for measuring the level of existing six financial knowledge aspects in respect of restaurant entrepreneurs, namely financing, record keeping and accounting, cash management, cost calculation, business planning, and a feasibility study. Section 3 comprised items to measure the level of financial knowledge acquisition using six financial knowledge aspects. Section 4 included items for measuring the level of need for KA tools using six financial knowledge aspects (see Appendix 2).

The researchers decided to use a five-point Likert scale in Sections 3 and 4 because prior related studies involving SMEs used a similar scale (Alam, Abdullah, Ishak, \& Zain, 2009; Tan, Chong, Lin, \& Eze, 2010). The five-point Likert scale ranged from 1 "least agree" to 5 "most agree".

Validity and reliability According to (Anderson \& Gerbing, 1988), it is necessary to examine the validity and reliability of variables. For the validity of the questionnaire, five academic business school faculty members were given the questionnaire and asked to examine it for meaningfulness, relevance, and clarity in order to evaluate the Index of Item Objective Congruence (IOC). Minor modifications were made based on the 
questionnaire in response to the suggestions received by five academic business school faculty members. The revised questionnaire was pre-tested on 30 restaurant entrepreneurs and improved and finalised on the basis of their feedback.

Reliability analysis was conducted to ascertain the consistency and stability of the questionnaire. The researchers applied Cronbach's alpha as the internal scale reliability measurement to assess the correlation of items in the questionnaire (Kerlinger, 1964). This study calculated the composite reliability coefficients in compliance with (Bagozzi \& Yi, 1988).

\section{Variables and measures Control variables}

Based on previous studies on education level and prior experience of launching a business were related to knowledge acquisition that supported a firm's survival (Carter \& Van Auken, 2006). Therefore, the researchers controlled seven variables that were age, education level, education background in business management, number of years of experiences, prior experience in restaurant business, responsibility for financial management, and responsibility for record keeping and accounting of each restaurant entrepreneur in order to better understanding the relationships among level of existing financial knowledge, the level of financial knowledge acquisition, and level of need for KA tools.

\section{Level of existing financial knowledge}

The restaurant entrepreneurs were asked to indicate the appropriate answer to the six questions on relevant financial knowledge for restaurant business management concerning financing, record keeping and accounting, cash management, cost calculation, business planning, and a feasibility study (see Appendix 2).

In order to measure the level of existing financial knowledge, the researchers distributed the levels of existing financial knowledge into four levels namely, "no financial knowledge" for restaurant entrepreneurs who provided correct answer for zero question, "low level of financial knowledge" for restaurant entrepreneurs who provided correct answer in the range of 1-2 questions, "moderate level of financial knowledge" for restaurant entrepreneurs who provided correct answer in the range of 3-4 questions, and "high level of financial knowledge" for restaurant entrepreneurs who provided correct answer in the range of 5-6 questions.

\section{Level of financial knowledge acquisition}

The restaurant entrepreneurs were asked to indicate the level of financial knowledge acquisition relevant to restaurant business management that was sorted into six categories: financing, record keeping and accounting, cash management, cost calculation, business planning, and feasibility study (see Appendix 2). The five-point Likert scale was used to measure the level of financial knowledge acquisition. The scale ranged from 1 "least agree" to 5 "most agree" in relation to the level of financial knowledge acquisition. In order to test the level of restaurant entrepreneur's financial knowledge acquisition, the researchers calculated the average level of financial knowledge acquisition of six financial knowledge aspects for each respondent. The higher number indicated a greater level of financial knowledge acquisition, while the lower number indicated less financial knowledge acquisition in each aspect.

Level of need for KA tools 
The restaurant entrepreneurs were asked to indicate the level of need for KA tools that were sorted into six categories: financing, record keeping and accounting, cash management, cost calculation, business planning, and a feasibility study (see Appendix 2).

In order to measure the level of need for KA tools, the five-point Likert scale was employed. The scale ranged from 1 "least agree" to 5 "most agree" in relation to the level of need for KA tools. The researchers calculated the average level for each respondent in order to test the level of need for KA tools. A higher number indicated a greater level of need for KA tools while a lower number indicated less level of need for KA tools.

Samples and data collection The target population of this study is small restaurant business entrepreneurs in Thailand. The researchers targeted the sample according to the selection criteria, namely small restaurant entrepreneurs who are owners of businesses with 50 employees or less, responsible for financial matters and decisionmaking.

In accordance with the study by Faul, Erdfelder, Lang, \& Buchner (2007), the researcher used the $G^{*}$ power analysis program for sample calculation. With a power of 0.80 , a significance level of 0.05 , and a medium effect size, the sample calculation using multiple linear regression with six predictors suggests a total sample size of 123 . Due to the likelihood of nonresponse and dropout, the researchers distributed 320 questionnaires to small restaurant entrepreneurs who met the selection criteria; 200 copies of the paper-based questionnaire were distributed at a restaurant exhibition where the potential respondents had established food kiosks, while another 120 copies of the onlinebased questionnaire were distributed to restaurant entrepreneurs through Line and Facebook. The researchers collected 135 valid paper-based questionnaires and another 37 valid online-based questionnaires. There were totally 172 valid questionnaires that was a greater than the number of sample size calculated for the power analysis. The total valid questionnaires caused $53.75 \%$ effective response rate.

\section{Results and analysis}

The IOC of all questions were above 0.5, and the Cronbach's alpha of 172 questionnaires on the level of existing financial knowledge, the level of financial knowledge acquisition, and the level of KA tools were $0.64,0.94$, and 0.89 , respectively. The descriptive statistics of all control variables were shown in Table 1, and the descriptive statistics of the level of existing financial knowledge can be found in Table 2.

Pearson's correlation analysis was used to assess the relationships among all variables. The results in Table 3 indicated the relationship between the level of existing financial knowledge, and the level of financial knowledge acquisition for record keeping and accounting $-0.225, p<.01$, cash management $-0.216, p<.01$, cost calculation $-0.156, p<.05$, business planning $-0.231, p<.01$, and a feasibility study $-0.270, p<.01$. Table 3 also demonstrated the relationship between the level of existing financial knowledge and the level of need for KA tools $0.151, p<$ .05. The relationships among the levels of financial knowledge acquisition for financing, record keeping, and accounting, cash management, cost calculation, 
Table 1 Demographic characteristics of the respondents

\begin{tabular}{|c|c|c|c|}
\hline \multicolumn{2}{|l|}{ Description } & \multirow{2}{*}{$\begin{array}{l}\text { Number of respondent } \\
25\end{array}$} & \multirow{2}{*}{$\frac{\text { Percent }}{14.5}$} \\
\hline Age & $<30$ & & \\
\hline & $30-40$ & 67 & 39.0 \\
\hline & $41-50$ & 63 & 36.6 \\
\hline & $>50$ & 17 & 9.9 \\
\hline & Total & 172 & 100.0 \\
\hline \multirow[t]{5}{*}{ Education level } & Below bachelor's degree & 57 & 33.1 \\
\hline & Bachelor's degree & 85 & 49.4 \\
\hline & Master's degree & 27 & 15.7 \\
\hline & Doctor's degree & 3 & 1.7 \\
\hline & Total & 172 & 100.0 \\
\hline \multirow[t]{3}{*}{ Background education* } & Business management & 43 & 25.0 \\
\hline & Hospitality management & 24 & 14.0 \\
\hline & Science & 13 & 7.6 \\
\hline \multirow[t]{6}{*}{ Number of years of experience } & $\leq 1$ year & 23 & 13.4 \\
\hline & $>1-3$ years & 41 & 23.8 \\
\hline & $>3-5$ years & 67 & 39.0 \\
\hline & $>5-10$ years & 21 & 12.2 \\
\hline & 11 years and above & 20 & 11.6 \\
\hline & Total & 172 & 100.0 \\
\hline \multicolumn{2}{|c|}{ Prior experience in a restaurant business } & 101 & 58.7 \\
\hline \multicolumn{2}{|c|}{ Responsible for financial management } & 52 & 30.2 \\
\hline \multicolumn{2}{|c|}{ Responsible for record keeping and accounting } & 127 & 73.8 \\
\hline
\end{tabular}

${ }^{*}$ Can be selected more than one item

business planning, and a feasibility study, and the level of need for KA tools were $0.466,0.339,0.402,0.464,0.442$, and 0.378 , respectively $(p<.01)$.

Hierarchical multiple regression was used to determine the level of existing financial knowledge, the level of knowledge acquisition for financing, record keeping and accounting, cash management, cost calculation, business planning, and a feasibility study, and the level of need for KA tools. Assumptions for multiple regression were checked.

Table 2 Level of restaurant entrepreneurs' existing financial knowledge

\begin{tabular}{llll}
\hline Level of existing financial knowledge & Number of correct answers & Number of respondent & Percent \\
\hline No financial knowledge & 0 & 39 & 22.7 \\
Low & 1 & 50 & \\
Total of low level & 2 & 35 & 49.4 \\
Moderate & 3 & 85 & \\
& 4 & 15 & 14.5 \\
Total of moderate level & & 10 & \\
High & 5 & 25 & 13.4 \\
& 6 & 22 & 100.0 \\
\hline
\end{tabular}




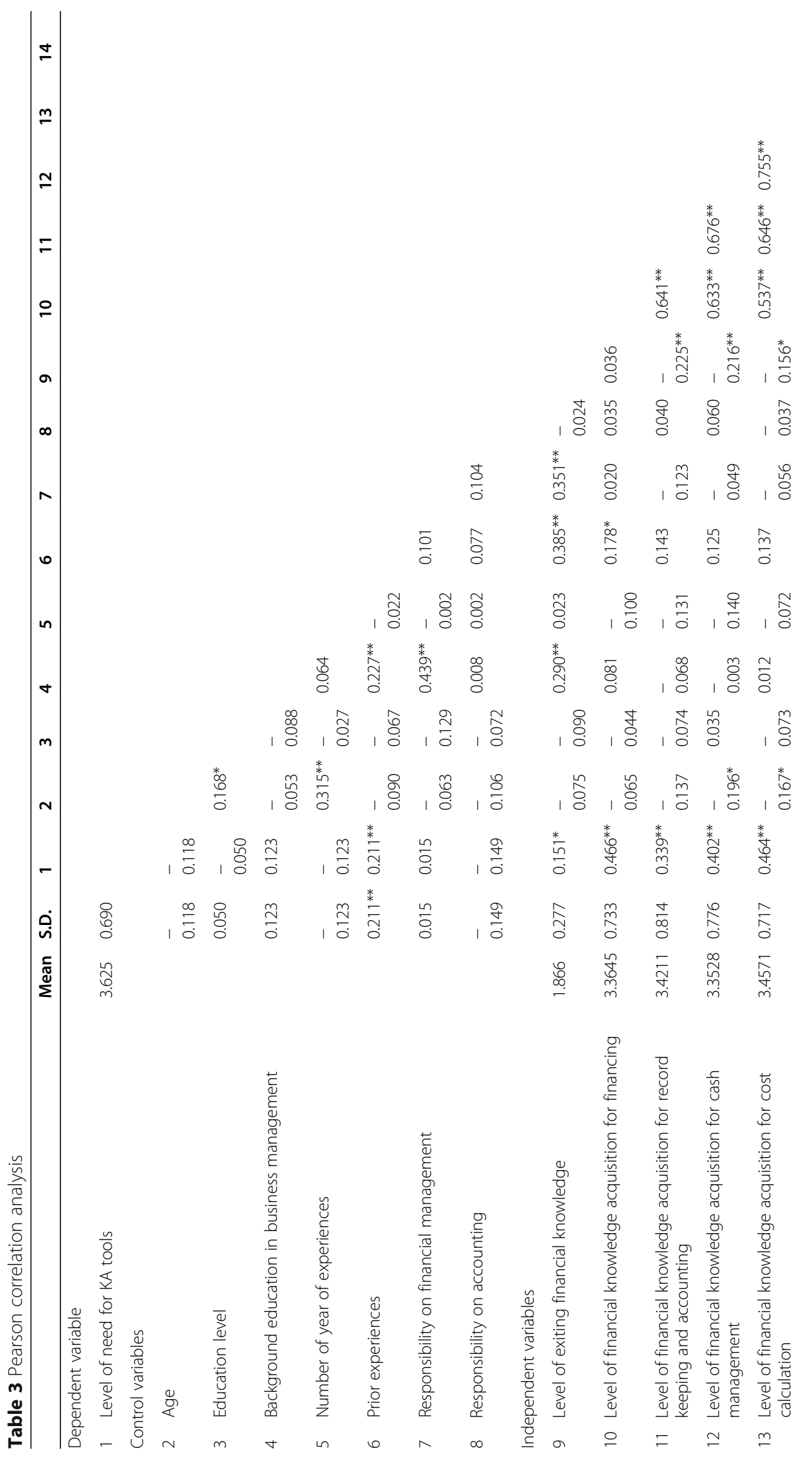




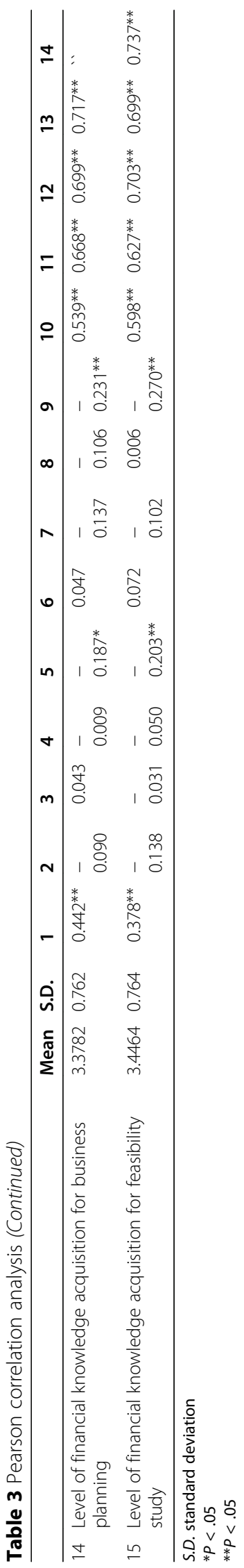


In order to examine the possibility of any effects derived from multicollinearity, the researchers determined the variance inflation factors (VIFs) of all variables. The VIFs were not exceeded four, thus eliminating the possibility of multicollinearity.

The results for the regression in the level of financial knowledge acquisition were shown in Table 4. The two-model regression analysis comprised the control variables and the level of existing financial knowledge as independent variables, and the level of financial knowledge acquisition as the dependent variable.

In Table 4, model 1 showed the effect of control variables that were unable to explain a significant portion of variance $\left(R^{2}=0.068, p<. n s\right)$ in the level of financial knowledge acquisition. Model 2 introduced the control variables together with the independent effect of the level of existing financial knowledge. The addition of the independent variables significantly explained the additional proportion of variance in the dependent variable $\left(R^{2}=0.142, p<.01\right)$. The full model revealed that prior experience in the restaurant industry before establishing a restaurant business and the level of existing financial knowledge were significant for explaining the variance in the level of financial knowledge acquisition.

$\mathrm{H} 1$ predicted a positive relationship between the level of existing financial knowledge and the level of financial knowledge acquisition. In Table 4, model 2 indicated that the level of existing financial knowledge explained the significant portion of the variance in the level of knowledge acquisition $(\beta=-0.734, p<.01)$. However, the variable was negatively related, and therefore, $\mathrm{H} 1$ was not supported.

In addition, hierarchical multiple regression was used to determine the level of need for KA tools. The results for the regression were shown in Table 5. The two-model regression analysis that comprised the control variables, the level of existing financial knowledge, and the level of financial knowledge acquisition in a set were independent variables, and the level of need for KA tools was the dependent variable.

In Table 5, model 1 indicated that prior experience in the restaurant industry before establishing a restaurant business and responsibility for business accounting were able

Table 4 Regression: Level of financial knowledge acquisition

\begin{tabular}{|c|c|c|c|c|c|}
\hline \multicolumn{2}{|c|}{ Variables } & \multicolumn{2}{|c|}{ Model 1} & \multicolumn{2}{|c|}{ Model 2} \\
\hline & & \multirow[t]{2}{*}{ Beta } & \multirow[t]{2}{*}{$t$ value } & \multirow[t]{2}{*}{ Beta } & \multirow[t]{2}{*}{$t$ value } \\
\hline & & & & & \\
\hline 1 & Age & -0.082 & -1.324 & -0.091 & -1.528 \\
\hline 2 & Education level & -0.006 & -0.237 & -0.009 & -0.361 \\
\hline 3 & Background education in business management & 0.019 & 0.149 & 0.058 & 0.467 \\
\hline 4 & Number of year of experiences & -0.072 & -1.615 & -0.065 & -1.527 \\
\hline 5 & Prior experience in the industry & 0.154 & 1.714 & 0.279 & $3.001^{* *}$ \\
\hline 6 & Responsibility on financial management & -0.165 & -1.385 & -0.038 & -0.321 \\
\hline 7 & Responsibility on record keeping and accounting & -0.041 & -0.124 & -0.055 & -0.506 \\
\hline \multicolumn{6}{|c|}{ Independent } \\
\hline \multirow[t]{4}{*}{8} & Level of exiting financial knowledge & & & -0.734 & $-0.372^{* *}$ \\
\hline & Model's $R^{2}$ & & 0.068 & & $0.142^{* *}$ \\
\hline & Adjusted $R^{2}$ & & 0.028 & & $0.099^{* *}$ \\
\hline & Change in $R^{2}$ & & 0.068 & & $0.074^{* *}$ \\
\hline
\end{tabular}

${ }^{* * P}<.01$ 
Table 5 Regression: Level of need for KA tools

\begin{tabular}{|c|c|c|c|c|c|}
\hline \multirow{2}{*}{\multicolumn{2}{|c|}{ Variables }} & \multicolumn{2}{|c|}{ Model 1} & \multicolumn{2}{|c|}{ Model 2} \\
\hline & & \multirow[t]{2}{*}{ Beta } & \multirow[t]{2}{*}{$t$ value } & \multirow[t]{2}{*}{ Beta } & \multirow[t]{2}{*}{$t$ value } \\
\hline & ntrol & & & & \\
\hline 1 & Age & $\overline{-} 0.063$ & -0.974 & $\overline{-} .025$ & $\overline{0}-430$ \\
\hline 2 & Education level & $\overline{0} .013$ & -0.470 & $\overline{0} .009$ & $\overline{0}-376$ \\
\hline 3 & Background education in business management & 0.152 & 1.132 & 0.072 & 0.619 \\
\hline 4 & Number of year of experiences & $\overline{0} .059$ & -1.276 & $\overline{0} .031$ & $\overline{0} .755$ \\
\hline 5 & Prior experience in the industry & 0.240 & $2.543^{*}$ & 0.085 & $0.936^{*}$ \\
\hline 6 & Responsibility on financial management & $\overline{0} .056$ & -0.453 & $\overline{0} .060$ & $-\overline{0.535}$ \\
\hline 7 & Responsibility on record keeping and accounting & $\overline{0}-267$ & $-{ }^{-} .270^{*}$ & $\overline{-}-196$ & $\overline{-} 1.887$ \\
\hline \multicolumn{6}{|c|}{ Independent } \\
\hline 8 & Level of exiting financial knowledge & & & 0.411 & $1.993^{*}$ \\
\hline 9 & Level of financial knowledge acquisition for financing & & & 0.260 & $2.837^{* *}$ \\
\hline 10 & $\begin{array}{l}\text { Level of financial knowledge acquisition for record keeping and } \\
\text { accounting }\end{array}$ & & & $\overline{-}-\mathbf{0 8 9}$ & - \\
\hline 11 & Level of financial knowledge acquisition for cash management & & & 0.005 & 0.056 \\
\hline 12 & Level of financial knowledge acquisition for cost calculation & & & 0.238 & $2.183^{* *}$ \\
\hline 13 & Level of financial knowledge acquisition for business planning & & & 0.186 & 1.799 \\
\hline \multirow[t]{4}{*}{14} & Level of financial knowledge acquisition for a feasibility study & & & $\overline{0} .025$ & $\overline{0}-249$ \\
\hline & Model's $R^{2}$ & & $0.101^{*}$ & & $0.366^{* *}$ \\
\hline & Adjusted $R^{2}$ & & $0.062^{*}$ & & $0.309^{* *}$ \\
\hline & Change in $R^{2}$ & & $0.101^{*}$ & & $0.265^{* *}$ \\
\hline
\end{tabular}

to explain a significant portion of variance $\left(R^{2}=0.101, p<.05\right)$ in the level of need for KA tools. Model 2 introduced the control variables together with the independent effect of the level of existing financial knowledge, a set of financial knowledge acquisition. The addition of the independent variables significantly explained the additional proportion of variance in the dependent variable $\left(R^{2}=0.366, p<.01\right)$. The full model revealed that the level of existing financial knowledge $(\beta=0.411, p<.05)$ was significant in the variance for explaining the level of need for KA tools.

$\mathrm{H} 2$ predicted a positive relationship between the level of existing financial knowledge and the level of need for KA tools. In Table 5, model 2 indicated that the level of existing financial knowledge explained a statistically significant proportion of the variance corresponding to the variable of the level of need for KA tools. Therefore, the result suggested that $\mathrm{H} 2$ was supported.

H3a predicted a positive relationship between the level of financial knowledge acquisition for financing and the level of need for KA tools. Examination of Table 5, model 2, indicated that the level of financial knowledge acquisition for financing explained a statistically significant proportion of the variance corresponding to the variable of the level of need for KA tools $(\beta=0.260, p<.01)$. Therefore, the result suggested that H3a was supported. 
H3b predicted a positive relationship between the level of financial knowledge acquisition in record keeping and accounting, and the level of need for KA tools. H3c predicted a positive relationship between the level of financial knowledge acquisition in cash management and the level of need for KA tools. Table 5 , model 2, showed that the level of financial knowledge acquisition in record keeping and accounting and cash management were not explained a significant proportion of the variance in the dependent variable $(\beta=-0.089$, ns) and $(\beta=$ 0.005 , ns), respectively. Therefore, the result suggested that $\mathrm{H} 3 \mathrm{~b}$ and $\mathrm{H} 3 \mathrm{c}$ were not supported.

H3d predicted a positive relationship between the level of financial knowledge acquisition in cost calculation and the level of need for KA tools. Table 5, model 2, indicated that the level of financial knowledge acquisition in cost calculation explained a significant proportion of the variance in the dependent variable $(\beta=0.238, p<.05)$. Therefore, the result suggested that H3d was supported.

H3e predicted a positive relationship between the level of financial knowledge acquisition in business planning and the level of need for KA tools. H3f predicted a positive relationship between the level of financial knowledge acquisition in the feasibility study and the level of need for KA tools. Table 5, model 2, showed that the level of financial knowledge acquisition for business planning did not explain a significant proportion of the variance in the dependent variable $(\beta=.186, \mathrm{~ns})$ and the level of financial knowledge acquisition for feasibility study did not explain a significant proportion of the variance in the dependent variable $(\beta=-0.025$, ns). Therefore, the result suggested that H3e and H3f were not supported.

\section{Discussion}

Although many prior studies exist on knowledge acquisition and financial knowledge for small business entrepreneurs, there are still significant research gaps. The findings of this study provide a model for extending knowledge acquisition, financial in particular, for small business entrepreneurs in a specific industry in developing countries such as Thailand. This study provides a better understanding of small business entrepreneurs and the relationship between the level of prior knowledge as the basis for existing financial knowledge in restaurant business management and knowledge acquisition. Moreover, it offers deeper insight into the role played by them in the need for KA tools.

Based on hypothesis 1, the researchers expect a positive relationship between the level of existing financial knowledge and the level of financial knowledge acquisition as the first research question. The regression result is not supported by the hypothesis. We found a negative relationship that restaurant entrepreneurs possessing a lower level of existing financial knowledge are more likely to acquire financial knowledge than others. This finding is not consistent with the studies by (Roper \& Love, 2017) in that the higher level of knowledge acquisition is determined by the higher level prior or existing knowledge base level.

Restaurant entrepreneurs in Thailand possessing less prior financial knowledge in restaurant business management are more likely to seek relevant financial knowledge. Due to the characteristics of restaurant entrepreneurs as new entrants, they take on a central position and have to play multiple business management roles. Therefore, they 
have to seek information, knowledge, and expertise in order for their business to survive which is consistent with the findings of Bridge et al. (2003).

Based on hypothesis 2, the researchers expect a positive relationship between the level of existing financial knowledge and the level of need for KA tools as the second research question. The regression result is supported by the hypothesis. We found that a higher level of existing financial knowledge encouraged restaurant entrepreneurs a higher need for KA tools.

According to the third research question on the relationships among the level of each financial knowledge acquisition aspect and the level of need for KA tools, we found the positive relationships of knowledge acquisition for obtaining a loan and cost calculation that have a significant impact on the need for KA tools.

As indicated by hypothesis 3a, the researchers expect a positive relationship between the level of knowledge acquisition in financing and the level of need for KA tools. The regression result is supported by the hypothesis. We found that restaurant entrepreneurs seeking knowledge in financing is more likely to need KA tools. This finding is consistent with previous studies by (Hyder \& Lussier, 2016); Usama et al. (2018) who found that undercapitalisation was related to small business bankruptcy, and entrepreneurs, therefore, must seek information and knowledge on obtaining adequate capital from financial institutions.

This hypothesis is evidenced by the response of restaurant entrepreneurs when asked to indicate the areas of financial knowledge acquisition impacting on their need for KA tools. They make an effort to search for information and knowledge when attempting to raise capital through a bank, and tentatively enquire about KA tools. KA tools can facilitate new entrepreneurs in accessing the necessary information and knowledge necessary for obtaining a loan from certain government banks who provide loans for new entrepreneurs, while other commercial banks do not. As a result, KA tools improve the chances of obtaining adequate capital and special interest rates, while saving time and facilitating effective business management. Therefore, knowledge acquisition in financing affects the need for KA tools.

Based on hypothesis $3 \mathrm{~b}$, the researchers expect a positive relationship between the level of knowledge acquisition for record keeping and accounting, and the level of need for KA tools. The regression result is not supported by the hypothesis. This finding is not consistent with Shallow (2017) who reported that small business entrepreneurs appreciate financial knowledge relevant to accurate record keeping and accounting enable efficiency in financial management. However, it is consistent with Orobia et al. (2013) in that small business entrepreneurs do not usually attach much importance to record keeping and accounting.

Most small business entrepreneurs in Thailand tend to achieve a low sales volume and there is a lack of strict regulations or incentives for record keeping and financial reports for this group of individuals. Consequently, restaurant entrepreneurs prefer to manage record keeping and accounting information in their minds rather than keeping a written record. This hypothesis is evidenced by the descriptive statistics that $62 \%$ of the studied samples are registered as individuals and another 13\% are non-registered entrepreneurs. Therefore, they cannot see the significance of record keeping and accounting 
Based on hypothesis 3c, the researchers expect a positive relationship between the level of knowledge acquisition for cash management and the level of need for KA tools. The regression result is not supported by the hypothesis. This study is not consistent with the finding of Ahmad (2016) in that small business entrepreneurs recognise the importance of cash management knowledge to strengthen financial management and financial survival.

Restaurant entrepreneurs tend to operate on a cash basis. As long as they have adequate cash to buy raw materials for their restaurants, little attention is paid to the acquisition of knowledge on cash management, as evidenced by the following comment:

Restaurant entrepreneur: "Umm...I seldom pay attention to cash management. As long as I have cash in hand to buy meat and vegetables, I can still operate my restaurant."

Based on hypothesis $3 \mathrm{~d}$, the researchers expect a positive relationship between the level of knowledge acquisition for cost calculation and the level of need for KA tools. The regression result is supported by the hypothesis. We found that the more restaurant entrepreneurs seeking knowledge on cost calculation is in greater need of KA tools. This finding is not consistent with the previous study by Oyadomari, Silva, Mendonca Neto \& Diehl (2017) in that small business entrepreneurs do not practice cost calculation. Due to the unique method used for cost calculation in the restaurant business, in order to accurately estimate the price of menu items, restaurant entrepreneurs tend to become concerned about knowledge acquisition and the need for KA tools

Based on hypothesis 3e, the researchers expect a positive relationship between the level of knowledge acquisition for business planning and the level of need for KA tools. The regression result is not supported by the hypothesis. The finding in this study is not consistent with those of Hopp and Greene (2018); Long et al. (2016) in that small business entrepreneurs recognise that knowledge of business planning is advantageous and leads to superior performance.

In Thailand, the majority of restaurant entrepreneurs run small, straightforward businesses with characteristic day-to-day management. Most of those in the study sample had prior experience as employees in a restaurant before establishing their own business, operating it in the same way. They did not appreciate the advantage of business planning as evidenced by the following interview.

Restaurant entrepreneur: “....on a business scale, my restaurant is not huge and complicated. We do business on a day-to-day basis. We don't know what will happen tomorrow. Long-term planning may not be advantageous for our business."

Based on hypothesis 3f, the researchers expect a positive relationship between the level of knowledge acquisition for a feasibility study and the level of need for KA tools. The regression result is not supported by the hypothesis. In previous studies, feasibility study knowledge affected small business performance (Okon \& Morgan, 2018). However, in this study, the findings were not consistent with previous research.

In Thailand, there are no business schools for small business entrepreneurs, particularly those involved in the restaurant entrepreneurs. They are unfamiliar with the concept of a feasibility study and fail to realise its advantages. Consequently, they seldom seek knowledge in relation to it. As evidenced by both the in-depth interview and 
survey questionnaire, only one restaurant entrepreneur mentioned the advantages of a feasibility study, and $21 \%$ sought knowledge on the concept.

The researchers found that most restaurant entrepreneurs in this study possess a low level of knowledge on the six financial aspects, with $22.7 \%$ having no financial knowledge and $49.4 \%$ possessing a low level of financial knowledge. This means that almost $75 \%$ of small restaurant entrepreneurs possess little financial knowledge and could face business failure. However, they are more likely to seek financial knowledge in order for their business to survive. As a result, KA tools tentatively support restaurant entrepreneurs in gaining greater financial knowledge, resulting in a decreased restaurant business failure rate.

\section{Conclusion}

In brief, this study demonstrates the significance of knowledge acquisition for small business entrepreneurs in relation to financial knowledge. This research extends the previous studies by proposing that a lower level of existing financial knowledge in small business entrepreneurs inhibits them from acquiring the additional knowledge essential for their business survival. In addition, relevant knowledge on how to raise capital and calculate costs accurately are the two most important aspects for encouraging such entrepreneurs to seek effective knowledge acquisition tools in order to acquire knowledge from outsiders. Relevant knowledge on how to raise a capital is essential to enable these entrepreneurs to raise adequate capital in the business start-up phase and expand it thereafter. Knowledge on how to accurately calculate costs is needed to support these entrepreneurs in realising the cost of raw materials, labour, and overheads. The entrepreneurs may have a satisfactory sales volume, but are not in profit due to a lack of concern about cost calculation, leading to financial difficulties and ultimately business failure.

Despite its limitations, this study makes an important contribution to the existing literature, extending the research of Roper \& Love (2017) in that lower level, prior knowledge leads small business entrepreneurs to acquire more financial knowledge since they tend to be responsible for all tasks related to business survival. Furthermore, six financial knowledge aspects in relation to restaurant entrepreneurs are identified, namely financing, record keeping and accounting, cash management, cost calculation, business planning, and a feasibility study. Consequently, the findings of this study can be used to encourage government authorities supporting small businesses to provide financial knowledge during the prestart-up phase; in particular, how to raise adequate capital and calculate costs as the first move towards improving the small business failure rate. Specific knowledge acquisition tools, particularly concerning the financial knowledge aspect should be employed to support these entrepreneurs in acquiring knowledge from outsiders.

The limitations of this study provide numerous opportunities for future research. There is still a need for better understanding of the different financial knowledge management practices and various uses of knowledge management tools and technology, since these can enable small business entrepreneurs to improve their performance, making a difference between success and failure. 


\section{Appendix 1}

Semi-structured questions

\section{To enquire about the existing financial knowledge of restaurant entrepreneurs}

1.1 What relevant financial knowledge of restaurant business management do you have?

1.2 Please explain how you would obtain a loan from the bank for your restaurant business.

1.3 Please explain how you conduct record keeping and accounting for your restaurant business.

1.4 Please explain how you operate cash management in your restaurant business.

1.5 Please explain how you calculate the cost price for your restaurant business.

1.6 Please explain how you construct a business plan for your restaurant business.

1.7 Please explain how you would construct a feasibility study for your restaurant business.

\section{To enquire about the current situation regarding the restaurant entrepreneur's financial knowledge acquisition relevant to restaurant business management}

2.1 How do you acquire financial knowledge relevant to restaurant business management?

2.2 If you want to obtain information or knowledge but cannot find it, how do you deal with this problem?

3. To enquire about the current situation regarding the restaurant entrepreneur's use of knowledge acquisition tools and technology

3.1 What kind of tools and technology do you use to acquire financial knowledge relevant to restaurant business management?

4. To enquire about the restaurant entrepreneur's need for financial knowledge relevant to the restaurant business

4.1 What financial knowledge relevant to the restaurant business management will support you in achieving success?

5. To enquire about the restaurant entrepreneur's need for financial knowledge tools and technology

5.1 What kind of tools and technology do you think could help you in accessing financial knowledge relevant to restaurant business management?

\section{Appendix 2}

Questionnaire on the current situation of existing financial knowledge, financial knowledge acquisition, and the need for financial knowledge acquisition tools and technology of restaurant entrepreneurs

Section 2 Questions on the existing financial knowledge of restaurant entrepreneurs

\section{Knowledge on financing}

Jane has been the owner of the Baby Shark seafood restaurant for a year. The business is not registered as a company. Since the restaurant is full of customers every day, they have to wait in a long queue. Therefore, Jane plans to expand the restaurant. She needs an investment of $\$ 10,000$ for the expansion. Currently, Jane has no collateral for a loan, 
but Murray her uncle is willing to act as guarantor. In this current situation, which bank should Jane approach for a loan?

A. Bank A offers loans to individuals who have run a business for at least three years. The individuals can guarantee the loans.

B. Bank B offers loans to individuals who have run a business for at least three years.

C. Bank $C$ offers loans to individuals who have operated a business for no more than three years. Individuals can guarantee the loans.

D. Bank D offers loans to companies that have operated a business for no more than three years. Individuals can guarantee loans.

\section{Knowledge of record keeping and accounting}

Christopher is the owner of the Exotic Panama restaurant. He wants to know how much profit his restaurant has made. What should Christopher consider in the accounting records?
A. Revenue and expenses
B. Revenue, expenses, debts, and equities
C. Revenue, expenses, assets, and liabilities
D. Cash, revenue, and expenses

\section{Knowledge of cash management}

Pat is the owner of Pat's Burgers. She needs cash to provide working capital in the short term. What should Pat not do?
A. Ask for a short-term loan from the bank
B. Draw cash from her own credit card
C. Borrow money from Ted, her uncle
D. Any of the above

\section{Knowledge of cost calculation}

Cindy is the owner of the Sweet Basil restaurant. She sells fried rice for £5. Raw materials cost $£ 2$ on average, shop rental is $£ 1500$ per month, the employee wages are $£ 1000$ per month, and the average utility bills are $£ 500$ per month (total $£ 3000$ per month). How many dishes does she have to sell to break-even?
A. 1000
B. 1500
C. 1800
D. 2000

\section{Knowledge of business planning}

Marry is the owner of an Italian restaurant. She is constructing a business plan in support of a bank loan application. What details should not include in the business plan?
A. A marketing plan with SWOT analysis (strengths, weaknesses, opportunities, and threats)
B. Operational planning
C. Estimates of revenue and expenses
D. A spaghetti cream sauce recipe 


\section{Knowledge of a feasibility study}

Mark is planning to open a pizza house. He plans to invest $£ 100,000$ and forecasts revenue, expenses, and profit at $£ 13,000, £ 3000$, and $£ 10,000$ per month, respectively. How long will it take for him to break-even?
A. About 6 months
B. About 8 months
C. About 10 months
D. About 14 months

Section 3 Questions on the current situation regarding the financial knowledge acquisition of restaurant entrepreneurs

1. Acquiring knowledge on financing: Agree $1-5$

1.1 When planning to ask for a loan from the bank to invest in your restaurant business, you always acquire information and knowledge on the relevant conditions for such a loan and the application process.

1.2 You can acquire information and knowledge on the conditions for a loan and the application process.

1.3 Currently, you have the effective tools and technology to acquire information and knowledge on obtaining a loan from the bank for investing in your restaurant business.

2. To acquire knowledge on record keeping and accounting: Agree 1-5

2.1 You always acquire knowledge on record keeping and accounting for the restaurant business.

2.2 You can acquire knowledge on record keeping and accounting for the restaurant business.

2.3 Currently, you have the effective tools and technology to acquire knowledge on record keeping and accounting for the restaurant business.

3. To acquire knowledge about cash management: Agree 1-5

3.1 You always acquire knowledge on cash management for the restaurant business.

3.2 You can acquire knowledge on cash management for the restaurant business.

3.3 Currently, you have the effective tools and technology to acquire knowledge on cash management for the restaurant business.

4. To acquire knowledge on cost calculation: Agree 1-5

4.1 You always acquire knowledge on cost calculation for the restaurant business.

4.2 You can acquire knowledge on cost calculation for the restaurant business.

4.3 Currently, you have the effective tools and technology to acquire knowledge on cost calculation for the restaurant business.

5. To acquire knowledge on business planning: Agree 1-5

5.1 You always acquire knowledge on business planning for the restaurant business.

5.2 You can acquire knowledge on business planning for the restaurant business.

5.3 Currently, you have the effective tools and technology to acquire knowledge on business planning for the restaurant business.

6. To acquire knowledge on a feasibility study: Agree 1-5

6.1 You always acquire knowledge on a feasibility study for the restaurant business. 
6.2 You can acquire knowledge on a feasibility study for the restaurant business.

6.3 Currently, you have the effective tools and technology to acquire knowledge on a feasibility study for the restaurant business.

Section 4 Questions about the need for financial knowledge acquisition tools and technology by restaurant entrepreneurs: Agree $1-5$

1. You need to have the effective financial knowledge acquisition tools and technology to acquire information and knowledge on loan conditions and the application process.

2. You need to have the effective financial knowledge acquisition tools and technology to acquire knowledge on record keeping and accounting for the restaurant business.

3. You need to have the effective financial knowledge acquisition tools and technology to acquire knowledge on cash management for the restaurant business.

4. You need to have the effective financial knowledge acquisition tools and technology to acquire knowledge on cost calculation for the restaurant business.

5. You need to have the effective financial knowledge acquisition tools and technology to acquire knowledge on business planning for the restaurant business.

6. You need to have the effective financial knowledge acquisition tools and technology to acquire knowledge on a feasibility study for the restaurant business.

Abbreviations

KA tools: Knowledge acquisition tools

Acknowledgements

This paper is part of a doctoral dissertation supported by a Graduate School Thesis Grant, Chulalongkorn University.

Authors' contributions

The authors have corrected and approved the submitted manuscript.

Authors' information

Panita Rachapaettayakom is a Ph.D. student at the Technopreneurship and Innovation Management Program, Graduate School, Chulalongkorn University. Her research interest includes small and medium businesses, entrepreneurship, financial and investment knowledge, knowledge management, and tools and technology in knowledge management.

Mongkolchai Wiriyapinit is an associate professor at Chulalongkorn University, Thailand. He is based at the Department of Commerce, Chulalongkorn Business School, Chulalongkorn University. He received his B.S. degree in 1997 from the University of Oregon. He received his M.Sc. degree in 2000 from London School of Economics and Political Science and Ph.D. degree in 2005 from the University of Warwick. His research interest includes knowledge management in large, medium, and small firms, and learning organisation in public and private agencies, knowledge management tools, and technology.

Nagul Cooharojananone is an associate professor at Chulalongkorn University, Thailand. He is based at the Department of Mathematics and Computer Science, Faculty of Science, Chulalongkorn University. He received his B.S degree in 1996 from Mahidol University. He received his M.E. and Ph.D. degree in 2000 and 2004 from the University of Tokyo. His research interest includes image processing, multimedia database, and information technology in knowledge management.

Suparatana Tanthanongsakkun is a lecturer at Chulalongkorn University, Thailand. He is based at the Department of Banking and Finance, Chulalongkorn Business School, Chulalongkorn University. He received his B. Eng., Industrial Engineering degree and M.S., Finance degree in 1994 and 1998 from Chulalongkorn University. He received his Ph.D., Finance degree in 2006 from Australian National University. His research interest includes business finance, investment, and capital market.

Nuttirudee Charoenruk is a lecturer at Chulalongkorn University, Thailand. She is based at the Department of Statistics, Chulalongkorn Business School, Chulalongkorn University. She received her B.S. (Statistics) degree in 2007 from Chulalongkorn University. She received her M.S. (Survey Methodology) in 2011 from the University of Michigan and Ph.D. (Survey Research and Methodology) in 2015 from the University of Nebraska-Lincoln. Her research interest includes statistics in survey research and methodology. 


\section{Availability of data and materials}

The datasets generated during and/or analysed during the current study are available from the corresponding author on reasonable request.

\section{Competing interests}

Authors have no competing interests.

\section{Author details}

${ }^{1}$ Technoprenurship and Innovation Management Program, Graduate School, Chulalongkorn University, Bangkok, Thailand. 'Department of Commerce, Chulalongkorn Business School, Chulalongkorn University, Bangkok, Thailand. ${ }^{3}$ Department of Mathematics and Computer Science, Faculty of Science, Chulalongkorn University, Bangkok, Thailand. ${ }^{4}$ Department of Banking and Finance, Chulalongkorn Business School, Chulalongkorn University, Bangkok, Thailand.

${ }^{5}$ Department of Statistics, Chulalongkorn Business School, Chulalongkorn University, Bangkok, Thailand.

Received: 7 April 2020 Accepted: 20 September 2020

Published online: 14 October 2020

\section{References}

Aghaei, S., Nematbakhsh, M., A., \& Farsani, H., K. (2012). Evolution of the World Wide Web: from Web 1.0 to Web 4.0. International Journal of Web \& Semantic Technology, 3(1), 1-10.

Ahmad, N. N. (2016). Cash management practices in micro and small businesses in Malaysia. Journal of Education and Social Sciences, 4, 331-335

Alam, S., Abdullah, Z., Ishak, N. A., \& Zain, Z. M. (2009). Assessing barriers of growth of food processing SMls in Malaysia: a factor analysis. International Business Research, 4(1), 252-259.

Ali, H., Omar, E. N., Nasir, H. A., \& Osman, M. R. (2018). Financial literacy of entrepreneurs in the small and medium enterprises. 31-38.

Anderson, J., \& C., \& Gerbing, D., W. (1988). An updated paradigm for scale development incorporating unidimensionality and its assessment. Journal of Marketing Research, 25(2), 186-192.

Bagozzi, R., \& Yi, Y. (1988). On the evaluation of structural equation models. Journal of the Academy of Marketing Science, 16(1), 74-94.

Berry, T., Sweeting, B., Goto, J., \& Taylor, M. (2002). Financial management practice amongst SMEs. Manchester: Manchester Metropolitan University.

Beverland, M. B., \& Lockshin, L. S. (2001). Organizational life cycles in small New Zealand wineries. Journal of Small Business Management, 39(4), 354-362.

Bridge, S., O'Neill, K., \& Cromie, S. (2003). Understanding Enterprise, Entrepreneurship and Small Business. Basingstoke and New York: Palgrave Macmillan.

Brinckmann, J., Grichnik, D., \& Kapsa, D. (2010). Should entrepreneurs plan or just storm the castle? A meta-analysis on contextual factors impacting the business planning-performance relationship in small firms. Journal of Business Venturing 25(1), 24-40. https://doi.org/10.1016/j.jbusvent.2008.10.007.

Carter, r., \& Van Auken, H. (2006). Small Firm Bankruptcy. Journal of Small Business Management, 44(4), 493-512.

Cho, T., \& Korte, R. (2014). Managing knowledge performance: testing the components of a knowledge management system on organizational performance. Asia Pacific Education, 15, 313-327.

Cohen, W. M., \& Levinthal, D. A. (1990). Absorptive capacity: a new perspective on learning and innovation. Admistrative Science Quarterly, 35(1), 128-152.

Currie, R. R., \& Wesley, F. (2010). Is it feasible? Positioning feasibility analysis as a valuable tool for assessing a potential tourism development. Tourism and Hospitality Planning \& Development, 7(4), 379-394.

Durst, S., \& Bruns, G. (2018). Knowledge management in small and medium-sized enterprises The Palgrave Handbook of Knowledge Management (pp. 495-514). Cham: Palgrave Macmillan.

Durst, S., \& Edvardsson, I. R. (2012). Knowledge management in SMEs: a literature review. Journal of Knowledge Management, 16(6), 879-903.

Faul, F., Erdfelder, E., Lang, A. G., \& Buchner, A. (2007). G* Power 3: a flexible statistical power analysis program for the social, behavioral, and biomedical sciences. Behavior research methods, 39(2), 175-191.

Frederiksen, D. L., \& Brem, A. (2016). How do entrepreneurs think they create value? A scientific reflection of Eric Ries' Lean Startup approach. International Entrepreneurship and Management Journal, 13(1), 169-189.

Fuller-Love, N. (2006). Management development in small firms. International Journal of Management Reviews, 8(3), 175-190

Ghani, S., \& R. (2009). Knowledge management: tools and techniques. Journal of Library \& Information Technology, 29(6), 3338.

Ha, S., Lo, M., \& Wang, Y. (2016). Relationship between knowledge management and organizational performance: a test on SMEs in Malaysia. Procedia-Social and Bahavioral Science, 224, 184-189.

Halabi, A. K., Barrett, R., \& Dyt, R. (2010). Understanding financial information used to assess small firm performance. Qualitative Research in Accounting \& Management, 7(2), 163-179.

Halil, F. M., Nasir, N. M., Hassan, A. A., \& Shukur, A. S. (2016). Feasibility Study and economic assessment in green building projects. Procedia - Social and Behavioral Sciences, 222, 56-64.

Hodges, H. E., \& Kent, T. W. (2006). Impact of planning and control sophistication in small business. Journal of Small Business Strategy, 17(2), 75-87.

Honig, B., \& Samuelsson, M. (2020). Business planning by intrapreneurs and entrepreneurs under environmental uncertainty and institutional pressure. Technovation, 102124

Hopp, C., \& Greene, F. J. (2018). In pursuit of time: business plan sequencing, duration and intraentrainment effects on new venture viability. Journal of Management Studies, 55(2), 320-351.

Huston, S., J. . (2010). Measuring financial literacy. The Journal of Consumer Affairs, 44(2), 296-316. . 
Hwang, G. J., \& Wu, P. H. (2014). Applications, impacts and trends of mobile technology-enhanced learning: a review of 20082012 publications in selected SSCl journals. International Journal of Mobile Learning and Organisation, 8(2), 83-95.

Hyder, S., \& Lussier, R. N. (2016). Why businesses succeed or fail: a study on small businesses in Pakistan. Journal of Entrepreneurship in Emerging Economies, 8(1), 82-100.

Jindrichovska, I. (2013). Financial management in SME. European Research Studies, 16(4), 79-94.

Joo, S. H., \& Grable, J. E. (2000). Improving employee productivity: the role of financial counseling and education. Journal of Employment Counseling, 37(1), 2-15.

Kerlinger, F. N. (1964). Foundation of behavioral research. New York: Holt. Rinehart \& Winston.

Kheradmand, M., \& Jafari, M. (2015). Effect of the knowledge acquisition on the strategic decision-making of industrial units' managers. European Journal of Business and Management, 7(17), 121-131.

Kim, J. H., \& Im, C. C. (2017). The study on the effect and determinants of small-and medium-sized entities conducting tax avoidance. Journal of Applied Business Research, 33, 375-390.

Kostakis, H., Albayrak, T., Boskou, G., \& Palisidis, G. (2011). Modelling activity-based costing in restaurants. Journal of Modelling in Management, 6(3), 243-257.

Kotzè, L., \& Smit, A. (2008). Personal financial literacy and personal debt management: the potential relationships with new venture creation. South African Journal of Entrepreneurship and Small Business, 1(1), 35-50.

Kumar, S., \& Rao, P. (2016). Financing patterns of SMEs in India during 2006 to 2013 - an empirical analysis. Journal of Small Business \& Entrepreneurship, 28(2), 97-131.

Lange, J., E., Mollov, A., Pearlmutter, M., Singh, S., \& Bygrave, W., D. (2007). Pre-start-up formal business plans and post-start-up performance: a study of 116 new ventures. Venture Capital, 9(4), 237-256.

Laudon, K. C., \& Laudon, J. P. (2002). Essential of management information systems. New Jersey: Prentice Hall.

Liao, S., Wu, C., Hu, D., \& Tsui, K. (2010). Relationships between knowledge acquisition, absorptive capacity and innovation capability:an empirical study onTaiwan's financial and manufacturing industries. Journal of Information Science, 36(1), 1935 .

Liao, Y., \& Barnes, J. (2015). Knowledge acquisition and product innovation flexibility in. SMEs Business Process Management Journal, 21(6), 1257-1278.

Liu, S., \& Deng, Z. (2015). Understanding knowledge management capability in business process outsourcing. Management Decision, 53(1), 124-138.

Long, D., Geng, L., \& Shakeel, M. (2016). Antecedent factors of business planning in the new venture emergence in China. Chinese Management Studies, 10(3), 510-526.

Luo, P., Wang, H., \& Yang, Z. (2016). Investment and financing for SMEs with a partial guarantee and jump risk. European Journal of Operational Research, 249(3), 1161-1168.

Marriott, N., \& Marriott, P. (2000). Professional accountants and the development of a management accounting service for the small firm: barriers and possibilities. Management Accounting Research, 11(4), 475-492.

McKenzie, D. (2017). Identifying and spurring high-growth entrepreneurship: experimental evidence from a business plan competition. American Economic Review, 107(8), 2278-2307.

McMahon, R. G. P. (2001). Business growth and performance and the financial reporting practices of Australian manufacturing SME's. Journal of Small Business Management, 30(2), 152-165. .

Moy, J. W., \& Luk, V. W. M. (2003). The life cycle model as a framework for understanding barriers to SME growth in Hong Kong. Asia Pacific Business Review, 10(2), 199-220.

Mungal, A., \& Garbharran, H. L. (2014). The perceptions of small businesses in the implementation of cash management techniques. Journal of economics and behavioral studies., 6(1), 75-83.

Mutua, J. M. (2015). Effect of bookkeeping on the growth of small and medium enterprises in Chuka Town. European Journal of Business and Social Sciences, 4(7), 102-112.

Ng, F., Harrison, J., \& Akroyd, C. (2013). A revenue management perspective of management accounting practice in small businesses. Meditari Accountancy Research, 21(2), 92-116.

Nwarogu, I. A., \& lormbagah, A. J. (2017). Cash management and performance of listed firms in Nigeria. Journal of Economics, Management and Trade, 18(1), 1-13.

Office of Small and Medium Entreprises Promotion (OSMEP) (2017). White Paper on Small and Medium Enterprises of Thailand in 2017. Thailand: Bangkok.

Okon, E. E., \& Morgan, M. O. (2018). The potency of feasibility analysis on business survival in Cross River State Southern Senatorial District, Nigeria. Global Journal of Social Sciences, 17(1), 69.

Ondiek, B. A., Deya, F. O., \& Busaka, J. N. (2013). Cash management techniques adopted by small and medium level enterprises in eldoret town, Kenya. Research Journal of Finance and Accounting, 4(18), 90-96.

Orobia, L., Byabashaija, W., Munene, J. C., Sejjaaka, S. K., \& Musinguzi, D. (2013). How do small business owners manage working capital in an emerging economy? Qualitative Research in Accounting \& Management, 10(2), 127-143.

Orser, B. J., Hogarth-Scott, S., \& Riding, A. L. (2000). Performance, firm size, and management problem solving. Journal of Small Business Management, 38(4), 42-58.

Oyadomari, J. C. T., Silva, R. M. d., Mendonça Neto, O. R. d., \& Diehl, C. A. (2017). An exploratory model of interventionist research to calculate costs and prices in small Brazilian manufacturers, combining training and intervention phases. Journal of Entrepreneurship in Emerging Economies, 9(3), 315-332. .

Papa, A., Dezi, L., Gregori, G. L., Mueller, J., \& Miglietta, N. (2018). Improving innovation performance through knowledge acquisition: the moderating role of employee retention and human resource management practices. Journal of Knowledge Management, 24(3), 589-605.

Raab, C., Mayer, K., \& Shoemaker, S. (2010). Menu engineering using activity-based costing: an exploratory study using a profit factor comparison approach. Journal of Hospitality \& Tourism Research, 34(2), 204-224.

Rachapaettayakom, P., Wiriyapinit, M., Cooharojananone, N., \& Tanthanongsakkun, S. (2018). An exploratory study on the knowledge management process, tools, and technologies in the context of small restaurant businesses in Thailand. Paper presented at the Paper presented at the 2018 7th International Conference on Industrial Technology and Management, Oxford, United Kingdom. 
Rafea, A., Hassenb, H., \& Hazmanc, M. (2003). Automatic knowledge acquisition tool for irrigation and fertilization expert systems. Expert Systems with Applications, 24, 49-57.

Ratten, V. (2014). Encouraging collaborative entrepreneurship in developing countries: the current challenges and a research agenda. Journal of Entrepreneurship in Emerging Economies, 6(3), 298-308.

Roper, S., \& Love, J. H. (2017). Knowledge context, learning and innovation: an integrating framework. Industry and Innovation, 25(4), 339-364

Sangree, \& David, J. (2012). Perform market analysis with a feasibility study for indoor waterpark resorts and outdoor waterparks. The Appraisal Journal, 149-156.

Scapens, R. W., \& Bromwich, M. (2001). Editorial report-management accounting research: the first decade. Management Accounting Research, 12(2), 245-254

Schierjott, l., Brennecke, J., \& Rank, O. (2018). Entrepreneurial attitudes as drivers of managers' boundary-spanning knowledge ties in the context of high-tech clusters. Journal of Small Business Management, 56(1), 108-131.

Shallow, K., \& N. (2017). Strategies for effective financial management in Vincentian small businesses, (pp. 70-92). America: Walden University.

Song, G., Min, S., Lee, S., \& Seo, Y. (2017). The effects of network reliance on opportunity recognition: a moderated mediation model of knowledge acquisition and entrepreneurial orinatation. Technological Forecasting and Social Change, 117, 98107.

Soundararajan, V., Jamali, D., \& Spence, L. J. (2018). Small business social responsibility: a critical multilevel review, synthesis and research agenda. International Journal of Management Reviews, 20(4), 934-956.

Soundararajan, V., Spence, L. J., \& Rees, C. (2016). Small business and social irresponsibility in developing countries: working conditions and "evasion" institutional work. Business \& Society, 57(7), 1301-1336.

Stal, J., \& Paliwoda-Pekosz, G. (2017). Mobile technology in knowledge acquisition: a preliminary study. In P. Ulman, R. Wegrzyn, \& P. Wojtowicz (Eds.), Knowledge-Economy-Society Challenges and Tools of Modern Finance and Information Technology. Krakow, Poland: Foundation of the Cracow University of Economics.

Taiwo, J. N. (2016). SMEs financing and its effects on nigerian economic growth. European Journal of Business, Economics and Accountancy, 4(4), 37-54.

Tan, K. S., Chong, S. C., Lin, B., \& Eze, U. C. (2010). Internet-based ICT adoption among SMEs: demographic versus benefits, barriers, and adoption intentions. Journal of Enterprise and Information Management, 23(1), 23(1), 27-55.

Tushabomwe-Kazooba, C. (2006). Causes of small business failure in Uganda: a case study from Bushenyi and Mbarara Towns. African Studies Quarterly, 8(4), 36-44.

Tyndale, P. (2002). A taxonomy of knowledge management software tools: origins and applications. Evaluation and Program Planning, 25, 183-190.

Unger, J. M., Rauch, A., Frese, M., \& Rosenbusch, N. (2011). Human capital and entrepreneurial success: a meta-analytical review. Journal of Business Venturing, 26(3), 341-358. https://doi.org/10.1016/j.jbusvent.2009.09.004.

Usama, K. M., \& Yusoff, W. F. W. (2018). The relationship between entrepreneurs'financial literacy and business performance among entrepreneurs of Bauchi State Nigeria. International Journal of Entrepreneurship and Business Innovation, 1(1), 1526.

Uwonda, G., Okello, N., \& Okello, N. G. (2013). Cash flow management utilization by small medium enterprises (SMEs) in northern Uganda. MERIT Research Journal of Accounting, Auditing, Economics and Finance, 1(5), 67-80.

Van Auken, H. E. (2005). A model of small firm capital acquisition decisions. International Entrepreneurship and Management Journal, 1, 335-352.

Wee, J., \& Chua, A. (2013). The peculiarities of knowledge management processes in SMEs: the case of Singapore. Journal of Knowledge Management, 17(6), 958-972.

Wong, K. Y., \& Aspinwall, E. (2004). Characterizing knowledge management in the small business environment. Journal of Knowledge Management, 8(3), 44-61.

Zait, A. (2015). Methodological options in economic and management research. Cross-Cultural Management Journal, 17(1(7)), 59-67.

Zait, D., \& Zait, A. (2009). Research anticipation: the methodological choice. Review of International Comparative Management, 10(5), 902-909.

Publisher's Note

Springer Nature remains neutral with regard to jurisdictional claims in published maps and institutional affiliations.

\section{Submit your manuscript to a SpringerOpen ${ }^{\circ}$ journal and benefit from:}

- Convenient online submission

- Rigorous peer review

- Open access: articles freely available online

- High visibility within the field

- Retaining the copyright to your article

Submit your next manuscript at $>$ springeropen.com 